\title{
PADRONIZAÇÃO NORMAL DAS FIBRAS NERVOSAS INTRAEPIDÉRMICAS EM 30 VOLUNTÁRIOS SAUDÁVEIS COM PGP 9,5
}

\author{
Luciana Moura ${ }^{1}$, Acary Souza Bulle Oliveira², Edmar Zanoteli ${ }^{3}$, \\ Ricardo Cardoso ${ }^{4}$, Beny Schmidt ${ }^{5}$, Alberto Alain Gabbai 6
}

\begin{abstract}
RESUM 0 - 0 recente método de avaliação das fibras nervosas intraepidérmicas com o PGP 9,5 vem se mostrando de grande utilidade no diagnóstico das neuropatias sensitivas de fibras finas, autonômicas e neuropatias periféricas subclínicas. Devido à variação da técnica relatada na literatura é de fundamental importância uma padronização normal. Estudamos 15 homens e 15 mulheres com média de idade de 34,5 anos. Em todos os voluntários foi real izada biopsia de pele na porção distal da perna. A média da densidade linear das fibras nervosas intraepidérmicas foi 5,3/mm com mediana de 6,0 e desvio padrão de 1,94. Essa técnica possui um grande número de vantagens em relação à biopsia de nervo convencional, é simples, pouco invasiva, reproduzível e pode ser repetida no mesmo paciente para avaliar progressão da neuropatia e possíveis respostas terapêuticas.
\end{abstract}

PALAVRAS-CHAVE: biopsia de pele, fibras sensitivas finas, nervos intraepidérmicos, PGP 9,5.

\begin{abstract}
Normal pattern of intraepidermal nerve fibers in 30 healthy volunteers with PGP 9.5
ABSTRACT - Skin biopsy has become an attractive technique to evaluate the terminal regions of small nerve fibers. There is extensive innervation of the skin by both sensory and autonomic fibers as demonstrated by staining for the pan-axonal marker PGP 9,5. The normal pattern is fundamental before any study, since three different techniques described in the literature with different results. Skin biopsy specimens of 3-mm in diameter were obtained from the distal leg of 30 healthy controls. Median intraepidermal nerve fiber density was $5.3 / \mathrm{mm}$. Skin biopsy may be a useful tool for assessing the topographic extent and degree of nerve fiber damage in sensory neuropathies and may be particularly useful in experimental treatment trials for peripheral neuropathies since, in contrast to standard nerve biopsy, the test can be repeated.
\end{abstract}

KEY WORDS: skin biopsy, small fibers, intraepidermal nerve fiber, PGP 9,5.

A presença de fibras nervosas na epiderme humana tem sido debatida e especulada há mais de 120 anos. A primeira descrição essencialmente correta sobre fibras nervosas intraepidérmicas (FNIE) foi publicada em 1868 por Langerhans, enquanto ele ainda era estudante de M edicina ${ }^{1}$. Usando a coloração de Cohnneim para cloreto de ouro ele mostrou ramos penetrando na epiderme através da membrana basal. Posteriormente, vários pesquisadores confirmaram a presença de nervos na epiderme ${ }^{2}$. Na maioria dos exemplos, as descrições eram acompanhadas por desenhos e raramente por foto- grafias. Outros métodos foram tentados, posteriormente, com a intenção de detectar a presença de fibras nervosas intraepidérmicas, como a prata e 0 azul de metileno. Devido à dificuldade técnica que esses métodos apresentaram no objetivo de demonstrar a presença de terminações nervosas livres na epiderme, vários investigadores negaram durante muito tempo a presença de tais elementos na epiderme humana. Mais recentemente, com técnicas de imunohistoquímica para identificação de neurotransmissores como a substância $P$, produto gênico relacionado ao gene da

Setor de Investigação em Doenças Neuromusculares, Disciplina de Neurologia, Departamento de Neurologia e Neurocirurgia da Universidade Federal de São Paulo - Escola Paulista de M edicina,São Paulo SP, Brasil (UNIFESP-EPM): 'Doutoranda em Medicina da UNIFESP-EPM; ${ }^{2}$ Doutor em M edicina pela UNIFESP-EPM médico neurologista responsável pelo Setor de Investigação em Doenças Neuromusculares da UNIFESP-EPM; ${ }^{3}$ Doutor em Medicina pela UNIFESP-EPM; ${ }^{4}$ M atemático, Especialista em matemática educacional para Estatística e Psicologia - Faculdade M etropolitana Unida (FMU); ${ }^{5}$ Professor Adjunto do Departamento de Anatomia Patológica da UNIFESP-EPM ; ${ }^{6 P r o f e s s o r ~ T i t u l a r ~ d o ~ D e p a r t a m e n t o ~ d e ~ N e u r o l o g i a ~ e ~ N e u r o c i r u r g i a ~ d a ~ U N I F E S P-E P M . ~ P e s q u i s a ~ c o m ~ a p o i o ~ d a ~ F A P E S P ~}$ - Processo 99/12157-2

Recebido 9 Junho 2003, recebido na forma final 2 Outubro 2003. A ceito 13 Novembro 2003.

Dra. Luciana Moura - Setor de Investigação de Doenças Neuromusculares da UNIFESP-EPM - Rua Pedro de Toledo 377 - $04039-031$ São Paulo SP - Brasil. E-mail: lucianamalves@terra.com.br 
calcitonina, a enolase neurônio específica e, principalmente, com o produto gênico anti-proteíco (marcador pan-axonal) PGP 9,5 , a visualização das fibras nervosas intraepidérmicas tornouse método bastante atraente e de grande sensibilidade para estudo desses terminais nervosos, tanto em padrões normais de distribuição da inervação, como em outros componentes neurais da pele, e em situações patológicas do sistema nervoso periférico, em especial nos processos que comprometem as fibras mielínicas de pequeno calibre e as amielínicas ${ }^{3,4}$.

Algumas das neuropatias periféricas, incluindo as relacionadas ao diabetes e à síndrome da imunodeficiência adquirida (AIDS), são caracterizadas por sintomas predominantemente sensitivos com maior degeneração das fibras nervosas na sua porção mais distal, caracterizando as neuropatias distais de fibras finas, as quais podem ser de difícil confirmação diagnóstica, principalmente se o quadro for recente ou o paciente assintomático5,6. Os métodos de diagnóstico de neuropatias de fibras finas e de quadros iniciais assintomáticos de outras neuropatias, que incluem a eletroneuromiografia convencional, o teste de limiar sensitivo (QST), o reflexo axonal sudomotor (QSART) e a biopsia de nervo convencional, ainda não possuem isoladamente uma sensibilidade adequada para 0 diagnóstico desses $\operatorname{casos}^{7-9} . \mathrm{A}$ biopsia de pele para estudo dos nervos intraepidérmicos apresenta sensibilidade maior do que os métodos citados acima para a avaliação dessas neuropatias ${ }^{8}$.

Como o método para avaliação das fibras nervosas intraepidérmicas (FNIE) é relativamente novo e existem pelo menos três técnicas diferentes descritas na literatura, é de fundamental importância que qualquer centro de estudo que se proponha a fazer uso dessa técnica possua um grupo de controles normais com características semelhantes, principalmente em relação à idade dos pacientes que serão estudados. A padronização do local da biopsia também tem grande importância, pois dois trabalhos na literatura ${ }^{1,10}$ já provaram haver variação na densidade de fibras nervosas intraepidérmicas a depender do local biopsiado, com gradiente rostro-caudal bem definido. A região do corpo humano que parece possuir maior densidade de fibras nervosas intraepidérmicas é a região dorsal' ${ }^{1}$.

0 objetivo do presente estudo foi estudar o padrão normal de distribuição das fibras nervosas intraepidérmicas na porção distal do membro inferior direito de voluntários saudáveis.

\section{MÉTODO}

Foram estudados 30 voluntários saudáveis de ambos os sexos (15 homens e 15 mulheres) com faixa etária variando entre 20 e 47 anos. A média de idade entre os homens foi 35,4 anos, com menor idade de 20 e maior de 47 anos. Entre as mulheres a média de idade foi 33,7 com menor de 20 e maior de 46 anos. A média de idade de todos os controles foi 34.5 anos. Dezesseis controles eram brancos, dez negros e quatro mulatos. Entre os brancos, dez eram do sexo masculino e entre os negros sete eram do sexo feminino.
Os voluntários foram divididos em dois grupos quanto à faixa etária, pessoas de até 20 anos e pessoas acima de 20 anos. Todos os voluntários foram submetidos a anamnese com ênfase para história negativa de neuropatia hereditária, diabetes, alcoolismo, AIDS, uso de drogas, exposição a agentes tóxicos como solventes, mercúrio, chumbo e ouro, deficiências vitamínicas, neoplasias, comprometimento da tireóide, lesões de pele, doença vascular periférica e traumas na porção distal do membro inferior direito. Os indivíduos controles apresentavam exames séricos normais de glicemia e anti-HIV negativo. Os voluntários do grupo controle foram médicos, médicos-residentes, estudantes, técnicos e funcionários da Universidade Federal de São Paulo - Escola Paulista de M edicina (UNIFESP-EPM), que participaram voluntariamente da pesquisa. A presente pesquisa faz parte de projeto de doutorado aprovado pela comissão de ética da UNIFESP-EPM .

Obtenção do fragmento da pele - As biopsias de pele foram realizadas sob técnica estéril. Foi utilizado material descartável empregado especialmente para realização de biopsias de pele superficiais com aro afiado de aço inoxidável de $3 \mathrm{~mm}$ de diâmetro (Punch - Stiefel), após anestesia local da pele com $2 \mathrm{ml}$ cloridrato de lidocaína a 2 \% sem vasoconstrictor (Ariston Industrias Químicas Brasil). Após a realização da biopsia foi feita sutura com fio mononylon 4.0 que foi retirado pela pesquisadora 7 dias após a biopsia. Todos os voluntários foram biopsiados na porção lateral distal da perna direita, $8 \mathrm{~cm}$ acima do maléolo lateral.

Técnica imunohistoquímica - Após a retirada do fragmento de pele os mesmos foram imediatamente fixados na solução de Zamboni (20 gramas de paraformaldeído acrescido de $150 \mathrm{ml}$ de solução saturada duplamente filtrada de ácido pícrico e acrescido de gotas de hidróxido de sódio a 2,5 \% e aquecidos a 60 graus centígrados para dissociação do paraformaldeído em formaldeído e diluídos em $1000 \mathrm{ml}$ de tampão fosfato), tampão fosfato 3,31 gramas de $\mathrm{NaH2PO4.H2O} \mathrm{e} 33.77$ gramas de NaHPO4.7H2O em 1000 ml deágua destilada, com osmolaridade de $900 \mathrm{m0sm}$ e pH de 7,3 durante 18 horas a 4 graus centígrados. A seguir foram transferidas para uma solução crioprotetora de sucrose a $10 \%$ em tampão fosfato salino (PBS 0,01 M tampão fosfato com 0,15 M NaCl em pH de 7,4) a 04 graus centígrados em 5 trocas durante 24 horas. Os fragmentos de pele permaneceram na solução de sucrose de 2 a 6 dias nessa temperatura até serem congelados e secionados. 0 s fragmentos foram congelados em gel congelante (Tissue-Tec) na bandeja do criostato com temperatura de 30 graus centígrados negativos. Foram obtidos cortes com espessura de 15 micrômetros no criostato. Os cortes foram fixados em lâminas previamente tratadas e mantidos por no máximo 24 horas a 20 graus centígrados negativos até 0 processamento imunohistoquímico ${ }^{14}$.

As lâminas com os fragmentos de pele foram retiradas do freezer e colocadas em temperatura ambiente durante 60 minutos para secarem. Posteriormente, foram incubadas durante 15 minutos com solução bloqueadora de albumina de cavalo, 0,5 \% de Triton X em tampão PBS a 0,1 M em pH de 7,4 a temperatura ambiente de 22 graus centígrados. A seguir, foram incubados com 0 anticorpo primário policlonal PGP 9,5 (Chemicon) na diluição de 1:800 em solução bloqueadora descrita acima, durante 18 horas, em temperatura 
ambiente. A seguir, os fragmentos foram lavados três vezes durante 5 minutos cada lavagem com tampão PBS. Foi então utilizado 0 anticorpo secundário anticoelho lgG conjugado a fluoresceína diluído em solução bloqueadora na diluição de 1:80 durante 60 minutos em temperatura ambiente. A seguir os cortes foram novamente lavados três vezes durante 5 minutos cada lavagem em tampão PBS 0,1 M e montados em meio especial para fluorescência, sob lamínula de 4 $\mathrm{cm}$. As lâminas foram estocadas ao abrigo da luz na temperatura de 4 graus centígrados ${ }^{1,4}$.

Quantificação e análise das fibras nervosas intraepidérmicas- Para a análise quantitativa do número de fibras nervosas intraepidérmicas por milímetro de epiderme (densidade linear), os cortes foram observados em microscópio convencional de epifluorescência com objetiva de 20 e 40 X. A densidade linear foi obtida pela divisão do número total de fibras que atravessaram a membrana basal, pelo comprimento em milímetros da epiderme analisada, no nosso estudo $3 \mathrm{~mm}$, baseando-se na hipótese de que o comprimento da epiderme estava próximo do diâmetro do "punch" de pele de $3 \mathrm{~mm}$.

\section{RESULTADOS}

0 método proposto mostrou-se efetivo para avaliar a inervação intraepidérmica através de biopsia de pele. As fibras nervosas intraepidérmicas (FNIE) apresentaram-se brilhantes e bem visualizadas em todos os controles. Além das FNIE, foram observadas também glândulas sudoríparas e folículos pilosos. A contagem da densidade das FNIE apresentou entre os controles masculinos média de 4,9 fibras/mm com mínimo de 3,3 fibras/mm e máximo de 11,6 fibras/mm com mediana de 4,6 . Nos controles femininos a média foi 5,3 fibras $/ \mathrm{mm}$ com mínimo de 3,3 fibras/mm e máximo de 8,6 fibras $/ \mathrm{mm}$ com mediana de 6,0. Entre todos os controles a média foi 5,2 fibras/mm com mediana de 4,8 e desvio padrão de 1,84 . Os controles que apresentaram menor densidade linear de FNIE tiveram 3,3 fibras/mm e o que apresentou maior densidade de FNIE tinha 11,6 fibras/mm. Não houve diferença estatisticamente significativa na densidade linear das FNIE entre sexo, raça ou faixa etária.

A distribuição das fibras nervosas na epiderme obedecia a padrão semelhante em todos os controles, sendo que foram identificados 3 padrões de distribuição das FNIE: o mais comum foi a presença de vários ramos nervosos da derme penetrando a membrana basal e logo após ocorrendo ramificações que começavam na camada espinhosa da epiderme e que alcançavam até a camada granulosa e, posteriormente, a camada mais externa da epiderme em ramos muito finos e com discretos abaulamentos nas extremidades, semelhantes a pequenos sacos terminais (17 casos); a segunda distribuição mais freqüente foi a presença de ramos nervosos que penetravam a membrana basal e alcançavam a camada mais externa da epiderme como uma única fibra (10 casos). Por fim, fibras nervosas que apresentavam ramificações já bem próximas da camada mais externa da epiderme correndo paralelos

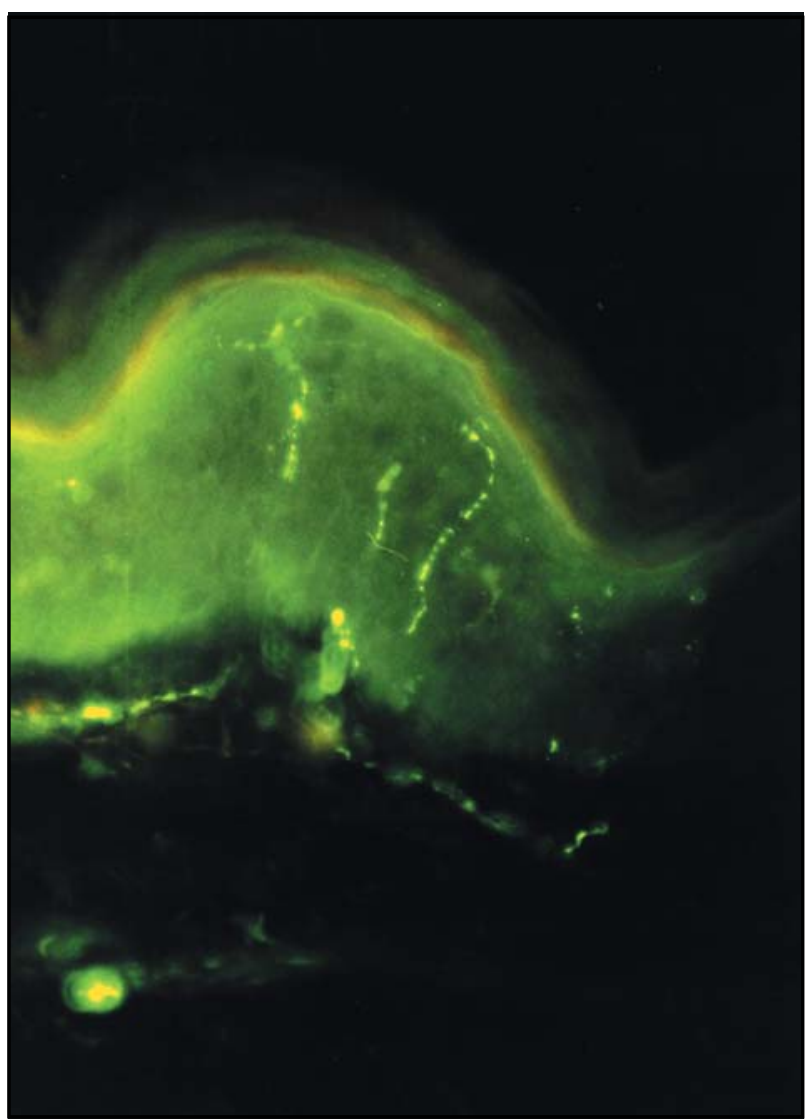

Fig 1. Inervação da epiderme em voluntário normal.

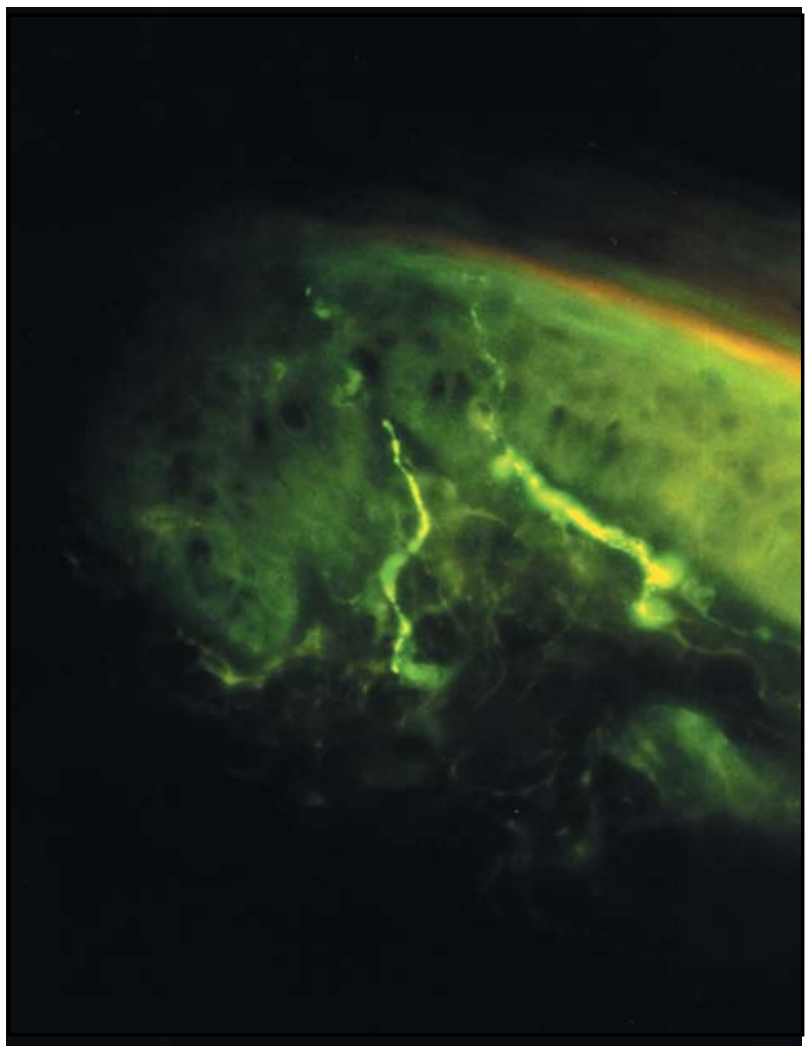

Fig 2. Nervo subepitelial enviando pequenos axônios que penetram a membrana basal da epiderme. 
a superfície da mesma por pequenas distâncias (3 casos).

Os controles negros possuíam apenas uma camada cómea (estratum corneum) mais espessa do que a encontrada nos controles brancos e mulatos. As inervações das glândulas exócrinas sudoríparas, dos vasos sanguíneos, dos músculos eretores dos pelos no folículo piloso e dos corpúsculos nervosos foram bem visualizados em todos os controles.

A biopsia de pele foi bem tolerada e sem complicações em todos os voluntários (Figs 1 e 2).

\section{DISCUSSÃO}

A presença de numerosas fibras nervosas em todas as camadas da epiderme humana foi bem demonstrada com 0 método proposto, sendo que essas fibras são presumivelmente terminais de nervos sensitivos e autonômicos. Não encontramos diferença estatisticamente significativa na densidade das FNIE entre raça e sexo, como já relatado por outros autores ${ }^{1,10}$. As faixas etárias analisadas também não apresentaram diferenças significativas; entretanto, não tivemos no nosso estudo pessoas com idades acima de 60 anos, sendo que a redução fisiológica no número de fibras nervosas está relatada na literatura como ocorrendo após os 60 anos. Em relação a outros estudos que avaliaram pessoas com idade acima de 60 anos e biopsia de pele, foi encontrado densidade linear maior em pacientes abaixo de 60 anos apenas no tronco, quando comparado com idades acima de 70 anos, nos dois grupos os padrões de variação rostro-caudal sendo similares ${ }^{1}$.

Não podemos no nosso estudo avaliar a variação rostrocaudal, pois foi realizada apenas uma biopsia de pele na porção distal da perna. Chien et al. ${ }^{11}$ estudaram a presença de neuropatia sensitiva de várias etiologias realizando uma biopsia de pele para estudo das FNIE na porção distal do antebraço e uma na porção lateral distal da perna. Eles encontraram que todos os pacientes com redução no antebraço tinham também redução na perna, o mesmo não acontecendo quando 0 achado estava só na perna, pelo que se pode concluir que, devido à natureza comprimento dependente das neuropatias, a realização de uma única biopsia na porção distal da perna é suficiente para a avaliação e diagnóstico de possíveis neuropatias sensitivas subclínicas ou de fibras finas. Este fato foi também confirmado por outro trabalho que concluiu que a região distal da perna (8 a $10 \mathrm{~cm}$ acima do maléolo lateral) seria o local mais indicado para realização das biopsias com objetivo de diagnóstico ${ }^{12}$.

0 padrão de distribuição das fibras na epiderme obedeceu a um padrão semelhante ao descrito por outros autores ${ }^{1,11,13-}$ 15 .

0 valor médio da densidade linear encontrado no nosso estudo é discretamente inferior ao do único trabalho realizado no Brasil com pacientes diabéticos e 18 controles normais, sendo que essa pequena diferença deve-se provavelmente ao fato da autora ter utilizado cortes de 50 micra para as reações ${ }^{16}$. Existem 3 métodos de avaliação das FNIE já descritos na literatura, que são: imunofluorescência com cortes espessos, uso de microscopia confocal e análise computadorizada de contagem ${ }^{13}$; imunofluorescência com cortes de 10 a 50 micrômetros e uso de microscopia óptica convencional|11,14; e imunoperoxidase com cortes de 25 micrômetros e uso de microscopia óptica convencional ${ }^{15}$. Devido a essas variações, antes de realizar comparações entre valores normais, às técnicas devem ser cuidadosamente avaliadas. Entre os autores que utilizaram técnica semelhante à nossa ${ }^{11,15,16}$, os valores entre os controles normais são próximos. Existem alguns estudos em que o valor do padrão normal é muito superior ao nosso. Esses são estudos que utilizaram cortes muito espessos (50 a 100 micrômetros), métodos de fixação diferentes, microscopia confocal e análise computadorizada das FNIE.

A contagem direta no microscópio, considerando o número de FNIE que atravessam a membrana basal dividindo-se por $3 \mathrm{~mm}$, baseando-se na hipótese de que o comprimento da epiderme, definido nos cortes está próximo do diâmetro do punch, que é de $3 \mathrm{~mm}$ foi também testada por outro autor, que concluiu ser uma metodologia válida, segura e reprodutível ${ }^{11}$. A técnica de contagem direta no microscópio foi também comparada com a computadorizada, e os autores encontraram que os métodos são comparáveis, ou seja, que o fato de realizar a contagem direta no microscópio, além de mais simples e rápido é também confiável ${ }^{9}$. Outro dado importante na análise da densidade das FNIE é a reprodutibilidade da técnica e a alta confiança entre observadores e intra-observador ${ }^{17}$.

\section{CONCLUSÃO}

O PGP 9,5 é um marcador pan-axonal que oferece a possibilidade de estudo das fibras nervosas intraepidérmicas com precisão; entretanto, o presente marcador não é capaz de explicar as funções especializadas desses nervos. O PGP 9,5 na inervação cutânea pode ser usado em estudos tanto de diagnóstico como de resposta terapêutica. No presente estudo, não podemos estabelecer o gradiente proximal-distal da densidade de inervação, já descrita por outros autores ${ }^{1}$, devido ao fato de ter realizado apenas um local de biopsia. Como já é conhecida a variação da densidade entre as várias partes do corpo e a possibilidade de variação com a idade, é de extrema importância à presença de material normal para comparação em qualquer estudo investigativo diagnóstico ou terapêutico. Essa técnica possui grande número de vantagens em relação à biopsia de nervo convencional; é pouco invasiva, possui baixa morbidade e pode ser repetida no mesmo paciente para avaliar progressão da neuropatia e possíveis respostas terapêuticas. A técnica laboratorial é simples e reprodutível, com baixa possibilidade de erros e que pode ser realizada em 
qualquer laboratório básico de imunohistoquímica sem nenhum equipamento especializado.

\section{REFERÊNCIA}

1. McCarthy BG, Hsieh ST, Stocks A, et al. Cutaneous innervation in sensory neuropathies: evaluation by skin biopsy. Neurology 1995;45:1848-1855.

2. Lacomis D. Small-fiber neuropathy. Muscle Nerve 2002;26:173-188.

3. Dalsgaard CJ, Rydh M, Hagerstrand A. Cutaneous innervation in man visualized with protein gene product 9.5 (PGP 9.5) antibodies. Histochemistry 1989;92:385-389.

4. McArthur JC, Stocks EA, Hauer P, Cornblath DR, Griffin JW. Epidermal nerve fiber density: normative reference range and diagnostic efficiency. Arch Neurol 1998;55:1513-1520.

5. Johansson O, Wang L, Hilliges M, Liang Y. Intraepidermal nerves in human skin: PGP 9.5 immunohistochemistry with special references to the nerve density in skin from different body regions. J Peripher Nerv Syst 1999;4:43-52.

6. Kennedy WR, Wendelschafer-Crabb G. The innervation of human epidermis. J Neurol Sci 1993;115:184-190.

7. Herrmann DN, Griffin JW, Hauer BS, Cornblath DR, McArthur JC. Epidermal nerve fiber density and sural nerve morphometry in peripheral neuropathies. Neurology 1999;53:1634-1640.

8. Lauria G, Holland N, Hauer P, Cornblath DR, Griffin JW, McArthur JC. Epidermal innervation: changes with aging, topographic location, and in sensory neuropathy. J Neurol Sci 1999;164:172-178.

9. Tobin K, Giuliani MJ, Lacomis D. Comparison of different modalities for detection of small fiber neuropathy. Clin Neurophysiol 1999;110:1909-1912.

10. Kennedy WR, Wendelschafer-Crabb G, Johnson T. Quantitation of epidermal nerves in diabetic neuropathy. Neurology 1996;47:1042-1048.

11. Chien Hsiung-Fei, Tseng To-Jung, Lin Whei-Min, et al. Quantitative pathology of cutaneuos nerve terminal degeneration in the human skin. Acta Neuropathol 2001;102:455-461.

12. Scott LJC, Griffin JW, Luciano C, et al. Quantitative analysis of epidermal innervation in Fabry. Neurology 1999;52:1249-1254.

13. Polydefkis M, Yiannoutsos CT, Cohen BA, et al. Reduced intraepidermal nerve fiber density in HIV-associated sensory neuropathies. Neurology 2002;58:115-119.

14. Stocks EA, McArthur JC, Griffin JW, Mouton PR. An unbiased method for estimation of total epidermal nerve fiber length. J Neurocytol 1996;25:637-644.

15. Periquet MI, Novak V, Collins MP, et al. Painful sensory neuropathy Prospective evaluation using skin biopsy. Neurology 1999;53:1641-1647.

16. Garibaldi SG. Contribuição da imuno-histoquímica cutânea na avaliação das fibras nervosas no diabete melito tipo 2. Tese - UNICAMP Campinas, 2001.

17. Hilliges $\mathrm{M}$, Johansson $\mathrm{O}$. Comparative analysis of numerical estimation methods of epithelial nerve fibers using tissue sections. J Periph Nervous System 1999;4:53-57. 